\title{
A Stop Motion for Moving Picture Machines
}

\author{
An Ingenious and Radical Improvement
}

\section{By W. B. Morton}

Ever since intermittent movement has been in use particular efforts have been made to make the movement of such characteristic that the least amount of strain would bear on the part to be moved.

In a continuous movement no force is required for the maintenance of the movement except to overcom incidental friction and windage.

In an intermittent movement, however, considerable forces are required to accelerate the masses from standstill to maximum velocity, and then again to retard the same masses from that maximum velocity to a standstill. If the accelerating force is constant during the whole time of acceleration a uniformly accelerated movement ensues.

The simplest form of such uniformly accelerated movement is given in that of a falling body whose velocity increases uniformly for successive time periods. We know that the force producing this movement is never less than the weight of the body, which remains constant from the time that it starts on its downward course. It is therefore evident that if we design for a movement of is therefore evident that if we design for a movement of to propel it must be constant. It is immaterial in that respect, whether the movement be a translatory, as in

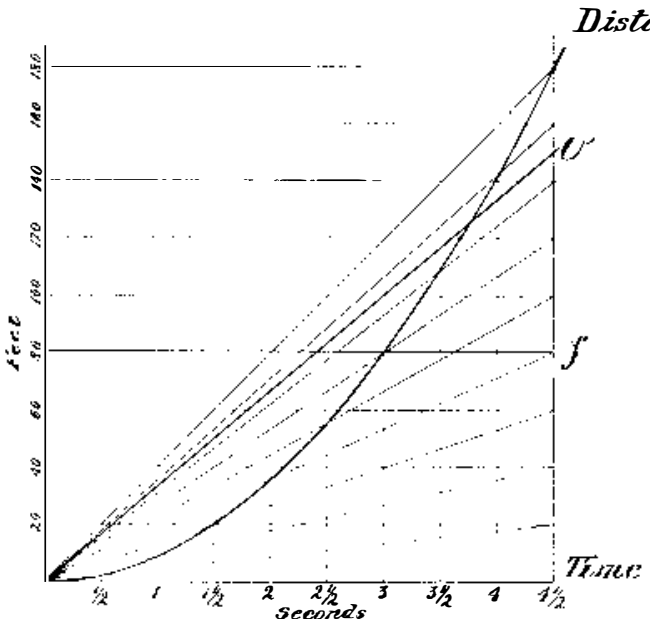

Fig. 1.-Diagram showing relation between distance traveled and time referred to a falling body.

the case with a falling body, or whether the movement sought is an angular one

To enable us, therefore, to produce the intermittent movement with a minimum amount of force acting at any time on the masses, it is important to design the "cam" in such way as to impart to the intermittent system an angular movement of uniform increment of velocity.

An intermittent movement which does not work on this principle of uniform power application, during all the time available, must needs act in such way as to require a greater force during one period to off set the deficiency of force during the other period. So that by deviating from the uniformly accelerated movement the maximum force required is greater than that uniform one which produces the movement of uniform acceleration. In Fig. $1 \mathrm{I}$ have shown the well known relation between the distance traveled and the time referred to $\mathrm{a}$

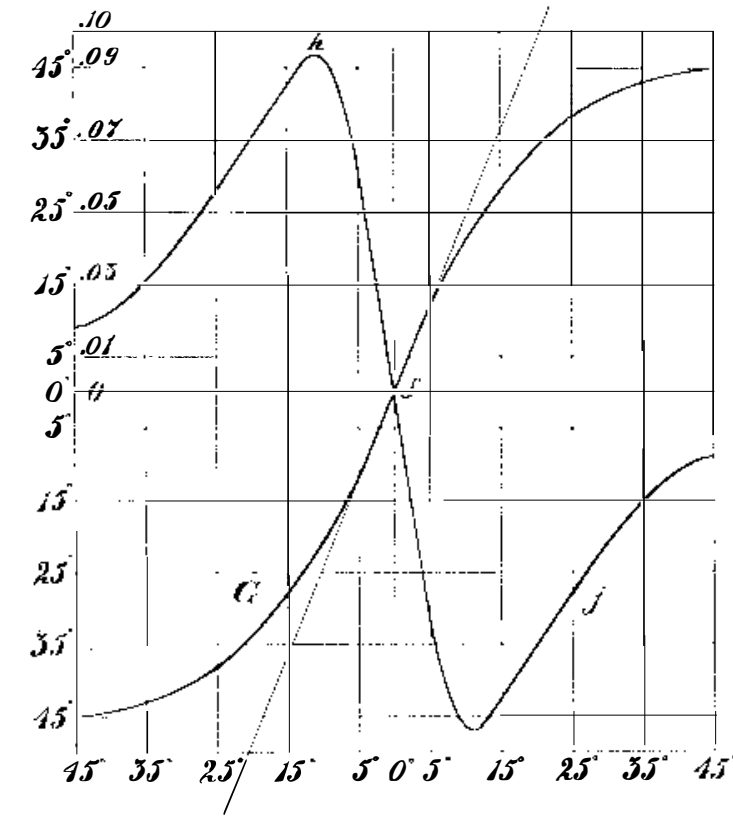

Fig. 3.-Movement of film in relation to Geneva stop movement. falling body. This curve is a parabola. To ascertain the velocity at any moment, we have only to determine the increment of the movement per unit time, or, expressed in other words, determine the differential quotient of this parabolic function at that moment. Both the geometric qualities of the parabola as well as the mathematical expression for its function lead to velocities which lie on a straight line emanating from the center

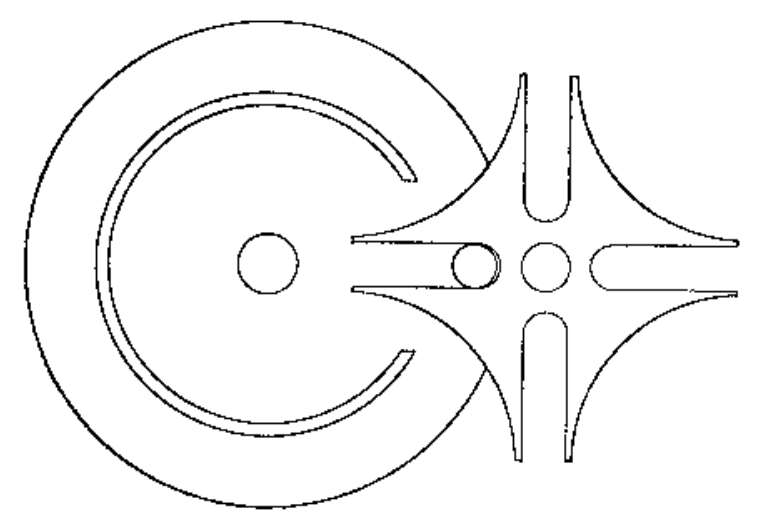

Fig. 2.-Four-slot Geneva movement.

of the co-ordinate system. In the diagram, Fig. 1, this velocity line is marked $v$

In general, the force required to produce velocity changes is given by the increment of the velocity, which in case of the straight velocity line $v$ is a constant designated $f$ in the diagram, Fig. 1 , as the increment of the velocity line $v$ is the same for all the points of the diagram.

The object of the intermittent movement in a motion picture projecting machine is to advance the film in as short a period as possible with a minimum strain on the moving parts. The requirement of quick movement is moving parts. The requirement of quick movement is
evident from the fact that during the movement the evident from the fact that during the movement the
shutter has to obliterate any possible light on the screen, and the longer the movement therefore the more the screen is deprived of useful light. On the other hand, the strain in moving parts has to be kept to a minimum to obviate undue vibration both of the machine and of

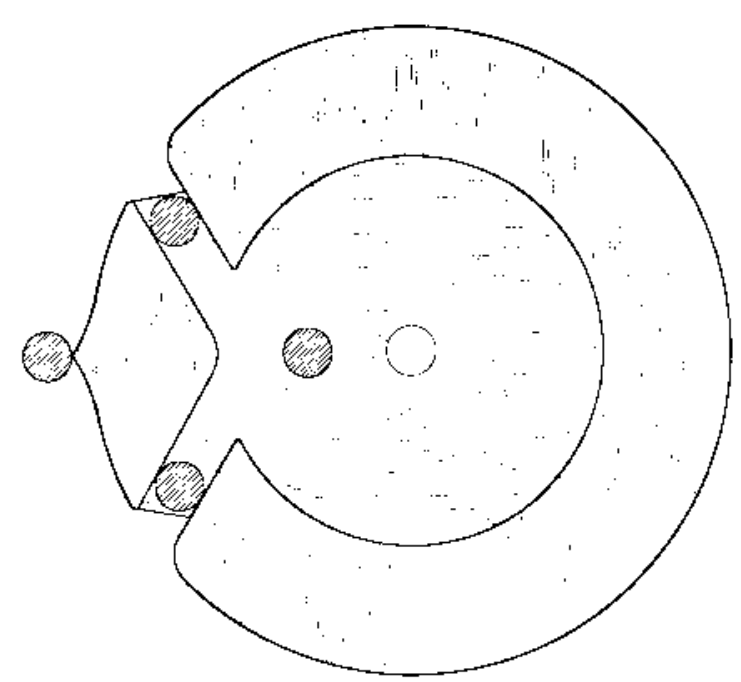

Fig. 4.-The Power cam

the film, and to minimize the wear on the delicate part of the machinery and on the sprocket holes in the film. It is deemed best to consider first the limitations of the intermittent movement generally known as Geneva movement.

In the Geneva movement the time required is exactly one quarter of the turn of the pin wheel. If the Geneva gear were made with five slots instead of four, as shown in Fig. 2, the movement would require one fifth of the revolution of the pin wheel; or, as it is usually expressed, in the four-slot Geneva, the movement and therefore of the film, covers 90 degrees of the fly wheel, whereas in five-slot Geneva, the movement and therefore of the film, is completed in 72 degrees of the fly wheel.

With the five-slot Geneva, the movement of the film requires one fifth of the time and the film, while stationary, could transmit the picture during four fifth of the time. With the four-slot Geneva, the film is moving during one fourth of the time and standing still three fourths of the time.

While we could therefore shorten the percentual time of movement of the film from $\mathbf{2 5}$ per cent in the four-slot
Geneva to 20 per cent in the five-slot Geneva, no means are possible by which to make a change anywhere between these two figures.

The four-slot Geneva, being universally adopted, precludes therefore the possibility of designing the machine for any other ratio of movement to rest, or darkness to light-transmission, than one to three.

In Fig. 3, the horizontal line denotes time, whereas the vertical lines may denote movement of the film. For the Geneva the movement is given by line $G$, which shows that from the beginning of engagement of the pin in the slot, the increase of the velocity of the film is extremely small; great increase in velocity, however, occurs at the point marked $h$. At the point $s$ the velocity of the film has reached the maximum, and from there on decreases in velocity more rapidly during a short period $j$, and finally comes to zero on position plus 45.

It will be seen that the work of the Geneva is done almost entirely in the two short periods $h$ and $j$, whereas little power is transmitted at the beginning or at the middle of the movement. The total strain of acceleration and the retardation of the film is therefore concentrated at two comparatively short periods of the whole time of movement and the wear of the Geneva slot and

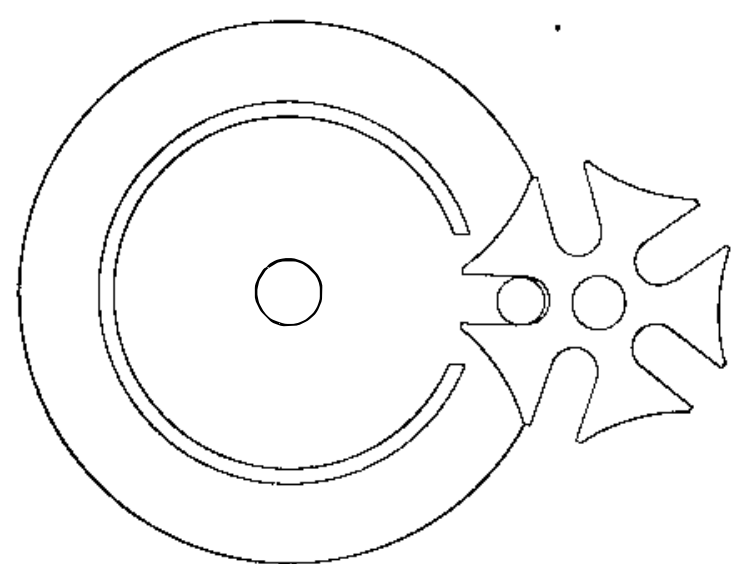

Fig. 7.-Five-slot Geneva movement.

pin as well as the intermittent sprocket's teeth and film holes becomes excessive.

To avoid such uneven and excessive force, both in the Geneva itself and on the film, Mr. Nicholas Power designed the cam movement, shown in Fig. 4.

This movement is not limited to any particular percentage for the movement of the film, the cam being designed for any number of degrees desired. The velocity of the film is diagrammatically shown in Fig. 5, which shows in comparison to Fig. 3 that the initial time of movement $m$ is utilized to better advantage for accelerating the film and thereby relieving the part $h$ of the diagram 3 of its excessive rise.

Such even distribution of power transmitted from the fly wheel to the intermittent, and from the sprocket to the film, accomplishes the total movement of the film to $3 / 4$ inch at a shorter time fly wheel, with a strain on the film, which can be gaged by the comparison of steepness of the angle $a$ as against the angle $A$.

To facilitate this comparison, Fig. 6 is shown whereln the movement as well as the forces required are shown

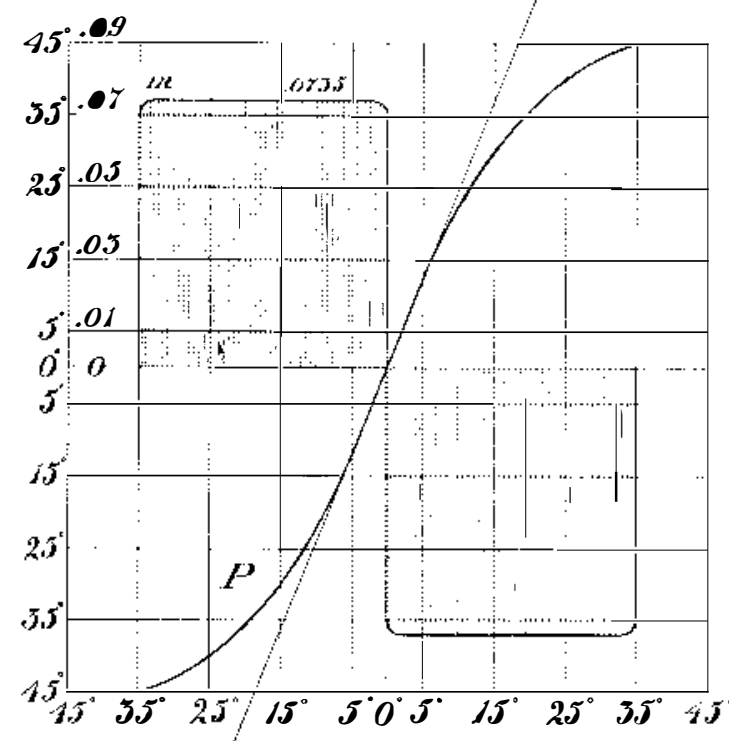

Fig. 5.-Movement of film as controlled by the new Power cam movement. 
mating to those of the Geneva and the Power eam. Mr. Power las therefore sumbined in this one design three changes of mechanical operations:

1. Shorter time of movement (71 degrees as against 90 degrees.

2. Uniform distribulion of strain over the whole period of movement, as against the unevenly divided action of the ceneva

3. Reduction in the engagement force from which three noticeable deserts are given in the operation:

1st. More light.

2d. Less vibration.

3d. Less wear both on the intermittent movement, intermittent sprocket and film.

An aroment might be advanced that, as above men-

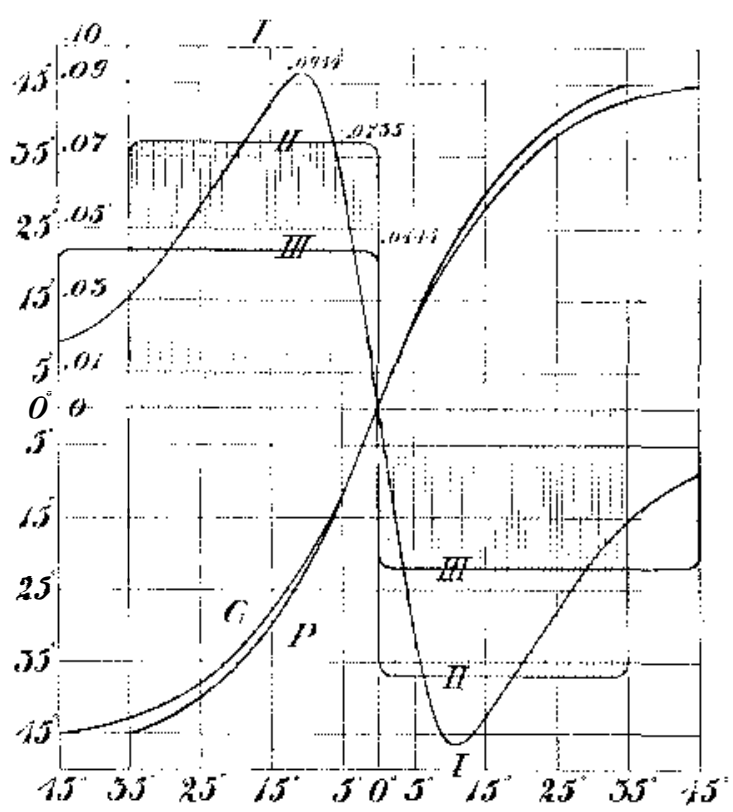

Fig. 6.-Comparison of movement and forces required by Geneva and Power movements.

\section{Unit Coal ${ }^{*}$}

Attention is called to the heat values for the "unit coal," the pure substance free from ash, moisture, sulphur, and other minor impurities. This value, like the coal-bed moisture may be regarded as the normal facto for the actual coal and does not vary in a given mine from year to year. If for example, the average unit value for a given mine is 14,350 British thermal unit per pøund of this material, any sample with whatever content of ash or moisture, when calculated to this "ontent of ash or moisture, when calculated to this "Init coal" basis, will give the same average value within the range of experimental error, or about 100 units in
14,000 , a variation of less than 1 per cent. This value 14,000 , a variation of less than 1 per cent. This value
enables us to check the correctness of the various de terminations, any one of which if seriously in erro would vitiate the result. Conversely, by reversing the calculation we are enabled to obtain a close estimate of the heat value present for any siven percentage of ash. This is of special value where it is desired to submit a bid for contracting in which a guarantee heat value is to be indicated. The formula by which this value is derived is as follows:

Unit B. t. u. $=\begin{aligned} & \text { Dry B. t. u. }-5000 S \\ & 1.00-(1.08 A+55 S)\end{aligned}$

In which $A$ is the weight of ash per gramme. $S$ is the weight of sulphur per gramme.

If every mine operator were to obtain as often as possible this "unit" value for his product, he could very shortly derive from an average of his $\log$ of values, basic factor which would be of great advantage to hin basic factor which would be of great advanta
in submitting propositions for coal supplies.

A special survey was recently made of certain mine in the five counties named in Illinois. The average of the "unit-coal" values for each mine may be taken as a constant for the output of that mine.

\begin{tabular}{|c|c|c|c|c|}
\hline & $\ldots$. & & UND. & .......... \\
\hline$N_{0}:$ & Gounly & $\begin{array}{l}\text { c!oul } \\
\text { bed }\end{array}$ & $\begin{array}{l}\text { Number of sam- } \\
\text { ples a veraged }\end{array}$ & $\begin{array}{l}\text { A verage }-\mathbf{B} \text {. t. u. } \\
\text { "unit coal" }\end{array}$ \\
\hline & thangtamon. & $i$ & 15 & 14,424 \\
\hline & Stingtrnon. & ij & 5 & 14,340 \\
\hline & Macoulin. . & ${ }^{i} \mathrm{i}$ & 6 & 14,310 \\
\hline & Madisen... & 6 & 18 & 14,350 \\
\hline & Vermilion. & 6 & 19 & 14,597 \\
\hline 6 & Vermilion... & 7 & 9 & 14,730 \\
\hline 7 & Williamson. & $\mathrm{ti}$ & 5 & 14,750 \\
\hline
\end{tabular}

The use which can be made of these "unit" values such as are shown in this table may be readily under* Bulletin 29, Mllinois State Geological Survey, by S. W. Parr.

${ }^{1}$ Illinois State Geological Survey, Bull. 16, p. 212, 1909 ${ }^{2}$ Pillar and storage coal will have heat units from 1 per
cent to 4 per cent below the values here given.

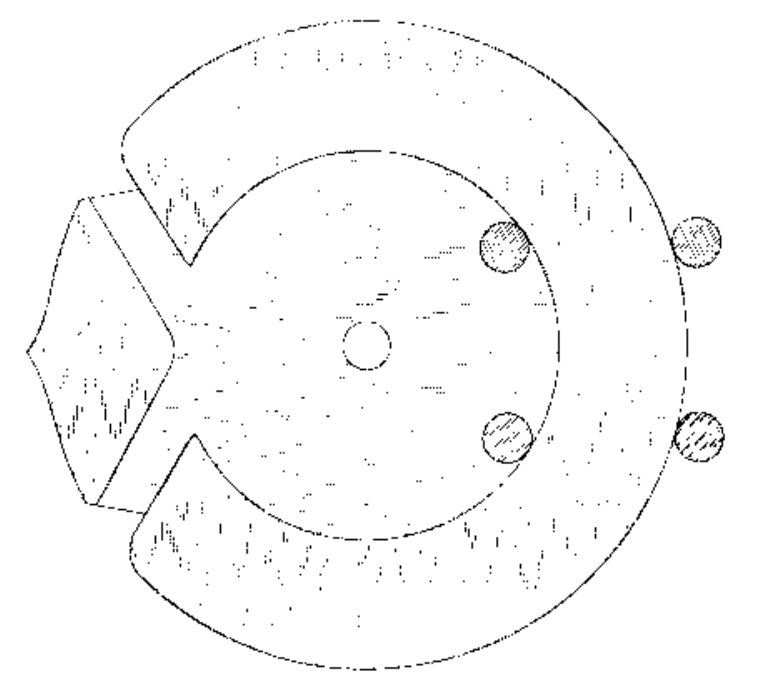

Fig. 8.--Another view of Power cam.

tioned, the Power cam shows more force transmitted during the initial part of the engagement than the Geneva movement, and in starting and therefore less destructive for the film, at least during this period of the engagement.

A rope will hardly last longer by being given plenty of rest mornings and evenings, but being overstrained beyond its safe capacity to a full day's work during the few hours of a day.

The work that the Geneva is not doing in the beginning of the movement, it has to make up during the short periods $h$ and $j$, causing jerks and ruining the film sprocket wheel and the slot and pin.

Comparing first the maximum force required for the Geneva with that of a Power cam of 90 degrees movement as given in III, we see that the latter requires a force which is less than one half of that required for the Geneva, the two absolute values being 0.44 as against 0.944

Such great superiority of the Power cam enables us, therefore, to reduce the time for its action and still remain with its actuating force below that of a Geneva. Such case has been shown in Fig. 6 by force line II which corresponds to the cam as incorporated in the projection machines manufactured. There the time has been reduced from an angle of 90 degrees to only 70 degrees, thereby reducing the dark period. It is true that by such quicker action the actuating force increases but as seen from line II it is still far below the force required of the Geneva, the relative values being 0.735 against 0.944

This comparison in Fig. 6 between the force line of the Geneva (I) and the Power cam as used (II), shows clearly the latter's advantage in reducing the time in a ratio of 70 degrees as against 90 degrees and reducing the actuating force in a ratio of 0.735 to 0.944 .
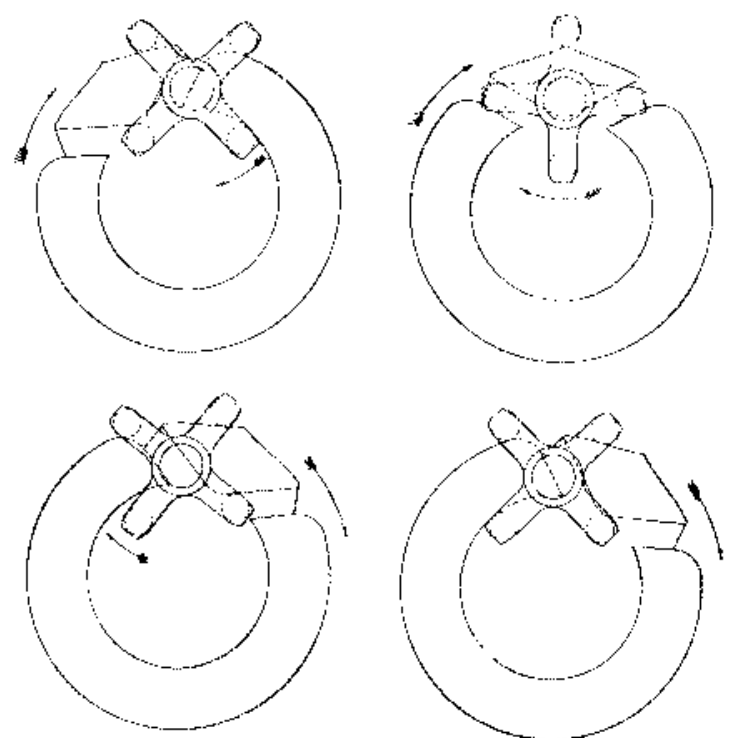

Fig. 9.-Diagrams illustrating operation of the Power cam. stood when it is remembere that each number represents material which is 100 per cent pure and that for each per cent of inert matter present, such as water and ash, there is a corresponding decrease in the number of heat units present. That is to say, if a coal has 20 per cent water and ash, then 80 per cent of the "unit" value will represent the heat units present per pound of coal as delivered. Indeed, it is possible by taking account of certain refinements, such as correction factors for sulphur and hydration of the shaly constituents, to make a calculation which will be of quite sufficient accuracy for basing bids and entering into contracts involving a guarantee as to heat values. The contracts involving a guarantee as to heat values. The
method of calculation is exceedingly simple and is method of calculation is exceed

Let $A=$ weight of ash per pound of coal.

Let $S=$ weight of sulphur per pound of coa

Then-

"Dry" B.t.u. $=$ "Unit" B.t.u. $\times 1.00-(1.08 A+$ $0.55 S$

To illustrate, take the "unit" value for coal from Ver milion County sample No. 6 in the table. Suppose we wish to know what heat values can be guaranteed on deliveries from a mine of this group on the basis that we can furnish material averaging as the "dry coal," 12 per cent ash, and 3 per cent sulphur, we will have our total non-combustible material corrected by the above formula as follows:

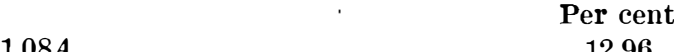

$$
\begin{aligned}
& \begin{array}{rrr}
1.08 A & \ldots \ldots \ldots \ldots \ldots \ldots \ldots \ldots \ldots \ldots \ldots, & 12.96 \\
0.55 S & \ldots \ldots \ldots \ldots \ldots \ldots \ldots \ldots \ldots \ldots & 1.65
\end{array} \\
& \begin{array}{c}
\text { Total } \ldots \ldots \ldots \ldots \ldots \ldots \ldots \ldots \ldots \\
100 \%-14.61 \%=85.39 \% .
\end{array} \\
& 14730 \times 85.39 \%=12578
\end{aligned}
$$

In this calculation the sulphur has been neglected. It has a small heat value equal to 5,000 times the weight of sulphur present or 50 times the percentage number. thus:

$50 \times 3=150$ units to be added to the above value, or

$$
\begin{aligned}
& 12578 \\
& 150 \\
& 12728 \text { B.t.u. }
\end{aligned}
$$

Deliveries from this mine, therefore, having ash, and sulphur as indicated above can be depended upon as carrying 12728 heat units per pound of "dry" coal, and this factor should be accurate within 100 units in 12,000 or less than a variation of 1 per cent from values as they would be determined by direct reading from an instrument. Any other set of values for ash and sulphur would similarly admit of ready calculation and should be use as a basis for calculations involving guarantees of deliveries on a heat-unit basis. If the heat units on the "wet" coal basis are desired assuming, for example, a moisture factor of 15 per cent, the above value as derived for "dry" coal should be multiplied by 0.85 , that is, 12728 B.t.u. $\times 0.85=10818$ B.t.u. per pound of the "wet" coal, assuming a moisture factor of 15 per cent as indicated. In this connection attention should be given to the assumed values which it is proposed to maintain for water and ash.

\section{Lightning Rods}

Even to-day really few people understand what occurs when there is a flash of lightning, or the part played by the lightning rod. Some very interesting and valuable information on these matters and on the protective range of lightning rods is given by J. and J. S. B. Larmor in the Proceedings of the Royal Society. Among other things they say: "Electric discharge in a gas is a rupture along a line of force, and not over a surface. The initial rupture is to be expected at a place of maximum force, and spreads in both directions along the line of force through that point. In the case a lishting bod the dischars pace summit of the rod, the place of most intense strain, and
strike away from the rod. Once a line of disruptive discharge is established, the neighborhood of a lightning rod can have little effect, and a simple mathematical investigation shows that a thin isolated rod will draw the discharge hardly at all unless in the region around its summit, and that the modification in the field due to a thin rod is negligible along its sides unless close to it. It is the building carrying the rod which modifies the field and directs discharge to its own upper parts, which, therefore, need protection by conductors adequate to draw off this discharge to earth; and vertica rods, joining together, if need be, lower down, but rising from the corners of the structure to a height which need not exceed about half its breadth, will lift up the field of concentrated electric force from the region directly above the building to the region above their summits, and will so take the discharge. The rods may rise from an earth-connected network spread over the roof but unless the meshes are fine enough to approximate to a complete metallic covering, it is questionable whether it would in itself protect a building from a discharge striking down upon it. A spread of connected metallic points some height above the building would appear to be more effective, and might even by themselves suffice to take up and guide away any likely stroke. In fact, if we neglect the discharge from the rods into the field their effect is merely to provide the easiest and most probable path for such discharges as may be attracted by the structure. The discharge from the pointed extremities of the rods adds, of course, to the protective effect by slowly, but continuously, reducing the strain in their neighborhood, and therefore the liability to dis ruptive discharge. 